\title{
Satisfação e insatisfação na Estratégia Saúde da Família: potencialidades a serem exploradas, fragilidades a serem dirimidas
}

\author{
Job satisfaction and dissatisfaction in the Family Health \\ Strategy: potentialities to be explored, fragilities to be reduced
}

\author{
Tamara Candido Mezari Milanez¹, Jacks Soratto' ${ }^{1}$, Fabiane Ferraz'1, \\ Marieli Mezari Vitali', Cristiane Damiani Tomasi ${ }^{1}$, Maria Teresa Sorato ${ }^{1}$, \\ Lisiane Tuon Generoso Bittencourt ${ }^{1}$
}

\begin{abstract}
Resumo
Introdução: A satisfação e insatisfação são aspectos que fazem parte do processo de trabalho em saúde. Objetivo: Este estudo teve como objetivo analisar os motivos de satisfação e de insatisfação dos profissionais de saúde que atuam na Estratégia Saúde da Família. Método: Trata-se de uma pesquisa exploratória descritiva, de abordagem qualitativa, realizada em um município de pequeno porte do sul do Estado de Santa Catarina, Brasil. A coleta de dados aconteceu com 16 profissionais da saúde, por meio de entrevistas semiestruturadas e observação direta, que foram analisadas segundo a técnica de análise de conteúdo categorial com o auxílio do software Atlas.ti. Resultados: Os resultados foram estruturados em duas macrocategorias, quais sejam, satisfação e insatisfação. A satisfação dos profissionais envolveu o reconhecimento do trabalho (usuário satisfeito e trabalho reconhecido), processo de trabalho (equipe, identificação e organização) e aspectos institucionais (jornada de trabalho e estabilidade). Já insatisfação relacionou-se aos aspectos de gestão do trabalho (salário, excesso de trabalho, condições de trabalho, estrutura física, sobrecarga, possibilidade de adoecimento, carência e sistema de informatização) e às dificuldades no relacionamento (com os usuários, com a equipe e falta de comunicação). Conclusão: A gestão do trabalho em saúde é o ponto central para potencializar aspectos associados à satisfação e suprimir elementos vinculados à insatisfação dos profissionais na Estratégia Saúde da Família. Palavras-chave: atenção primaria à saúde; sistema único de saúde; estratégia saúde da família; condições de trabalho; pesquisa qualitativa.
\end{abstract}

\footnotetext{
Abstract

Background: The job satisfaction and dissatisfaction are aspects of health work. Objective: The present study aimed to analyze the reasons for satisfaction and dissatisfaction among health professionals working at the Family Health Strategy. Method: This is an exploratory, descriptive, qualitative study conducted in a small municipality in southern Santa Catarina state, Brazil. Data from sixteen health professionals were collected through semi-structured interviews and direct observation, and were analyzed by content analysis using Atlas.ti software. Results: Results were grouped into two macro categories: job satisfaction and job dissatisfaction. Job satisfaction of the professionals included recognition of their work (satisfied users and recognized work), work process (team work, identification, and organization), and institutional conditions (work load and stability), whereas job dissatisfaction was associated with aspects of work management (salary, overwork, work conditions, physical structure, work overload, possibility of becoming ill, deficiency, and information system), and difficulties in relationship (with users and team). Conclusion: Health work management is the central aspect to increase job satisfaction and decrease the elements associated with professional dissatisfaction in the Family Health Strategy.

Keywords: primary health care; unified health system; family health strategy; work conditions; qualitative research.

${ }^{1}$ Universidade do Extremo Sul Catarinense (UNESC) - Criciúma (SC), Brasil.

Trabalho realizado no Município de Meleiro (SC), Brasil.

Endereço para correspondência: Jacks Soratto - Programa de Pós-graduação em Saúde Coletiva, Universidade do Extremo Sul Catarinense (UNESC), Av. Universitária, 1105, Bloco S, Sala 13, $1^{0}$ andar - Bairro Universitário - CEP: 88806-000 - Criciúma (SC), Brasil - jacks@unesc.net Fonte de financiamento: PIBIC/CNPq edital nº 015/2017 UNESC.
} 


\section{INTRODUÇÃO}

O Brasil, atualmente, conta com mais de 40 mil equipes de Saúde da Família (eSF) implantadas ${ }^{1}$, as quais são compostas por, no mínimo, médico generalista ou especialista em saúde da família, ou médico da família ou da comunidade, enfermeiro generalista ou especialista em saúde da família, auxiliar ou técnico de enfermagem e agentes comunitários de saúde. Além disso, podem ser acrescentados os profissionais de saúde bucal: cirurgião-dentista generalista ou especialista em saúde da família e auxiliar e/ou técnico em saúde bucal ${ }^{2}$.

As eSF têm responsabilidade sanitária por um território adscrito, com vistas à realização de ações voltadas à promoção, à proteção, à prevenção, ao diagnóstico, ao tratamento e à reabilitação de danos, monitorando a saúde com o objetivo de desenvolver uma atenção integral direcionada à autonomia do usuário e aos determinantes e condicionantes de saúde das coletividades.

Na Estratégia Saúde da Família (ESF), por existir essa inserção no território e por lidar com questões singulares geográficas, históricas, sociais e políticas, há uma exigência de maior comprometimento dos profissionais, tendo em vista a complexidade da sua atuação nas práticas de cuidado à saúde. Essa atuação ou a capacidade de exercitá-la no cotidiano da assistência em saúde pode gerar ou ser influenciada por aspectos que oportunizam a satisfação e a insatisfação desses profissionais que realizam o trabalho em saúde nesse importante espaço de atuação.

Alguns estudos ${ }^{3,4}$ realizados em ESF de município de grande porte demonstram que profissionais vivenciam cotidianamente situações que corroboram a insatisfação no trabalho, como baixo salário, falta de comunicação entre a equipe, ausência de funcionários, sobrecarga de serviço, entre outros. Por outro lado, também existem elementos que proporcionam a satisfação, a saber: o trabalho em equipe, o gosto pelo que faz etc. Descobrir se esses fatores existem e entender se eles se manifestam em um município de pequeno porte é o que motiva a realização desta pesquisa.

Diante do exposto, este estudo teve como objetivo: analisar os motivos de satisfação e de insatisfação dos profissionais de saúde que atuam na ESF de um município de pequeno porte do sul do Estado de Santa Catarina.

\section{MÉTODO}

A presente pesquisa é um estudo do tipo exploratório descritivo, com abordagem qualitativa ${ }^{5}$, balizado teoricamente pela Política Nacional de Atenção Básica ${ }^{1}$ e pelas reflexões sobre o processo de trabalho em saúde ${ }^{5,6}$.

O estudo foi realizado no município de Meleiro, sul do Estado de Santa Catarina, em duas Unidades de Saúde com três eSF. Os participantes foram 16 profissionais de saúde que compõem a equipe multiprofissional, a saber: quatro enfermeiros, quatro médicos, cinco técnicos de enfermagem, dois dentistas e um técnico de saúde bucal. A quantidade de participantes foi considerada suficiente segundo os critérios de saturação dos dados, ou seja, quando o pesquisador não encontra nos participantes da pesquisa mais explicações, interpretações ou descrições do fenômeno estudado ${ }^{7,8}$.

Os critérios para seleção foram: ESF que tenham classificação acima da média e muito acima da média, segundo os critérios do Programa Nacional de Melhorias do Acesso e da Qualidade de APS (PMAQ-AB); e ESF que possuam a equipe mínima completa. Foram excluídos do estudo Unidades de Saúde que possuem equipes mistas, ou seja, tradicional e ESF; e trabalhadores que compõem as ESF, como agentes comunitários de saúde, trabalhadores da área administrativa, limpeza e apoio.

A coleta de dados foi realizada por meio de entrevista semiestruturada e observação direta entre os meses de janeiro e março de 2017. As entrevistas aconteceram em um local apropriado nas Unidades de Saúde que participaram do estudo e contaram com um roteiro composto por perguntas fechadas para identificação dos participantes e perguntas abertas que enfatizavam o objeto de investigação deste estudo. Todas as entrevistas foram gravadas, totalizando 4 horas e 23 minutos. Após a gravação, elas foram transcritas em programa de edição de texto.

Por sua vez, a observação direta, que seguiu também um roteiro, foi utilizada como técnica complementar, com vistas a subsidiar os pesquisadores para a interpretação dos achados provenientes das entrevistas. Foram realizados dois períodos de observação, totalizando 9 horas e 30 minutos de observação.

Os dados foram organizados segundo os preceitos da análise de conteúdo categorial ou temática, a qual se divide em três fases: pré-análise, exploração do material e interpretação ${ }^{9}$. Contou-se com o auxílio do software Atlas.ti para análise de dados qualitativos ${ }^{10}$.

$\mathrm{Na}$ pré-análise, foram transcritas as entrevistas e as notas de observação em arquivo do Microsoft Word e realizada uma criteriosa leitura desse material, com correção ortográfica e ajustes linguísticos e gramaticais. Esse processo contou ainda com a retomada dos pressupostos e objetivos da pesquisa.

$\mathrm{Na}$ exploração do material, objetivou-se alcançar o núcleo de compreensão do texto. Nessa etapa, o principal objetivo foi a criação dos códigos e das categorias ou dos grupos de códigos. Os códigos (codes) foram criados a partir da seleção de falas dos participantes (quotations) representados por uma palavra ou por um conjunto de palavras que tipificam a fala dos entrevistados.

Após a criação dos códigos, houve o refinamento com vistas a fundir os códigos parecidos ortograficamente, para, posteriormente, agrupar os códigos em grupos de códigos (code group) ou subcategorias. As subcategorias foram construídas com base 
em duas macrocategorias, que foram definidas a priori, a saber: satisfação e insatisfação dos profissionais de saúde.

No tratamento dos resultados obtidos e na interpretação deles, realizou-se o processo de interferência, relacionando os códigos, os trechos de falas, as macrocategorias e as subcategorias com o quadro teórico e os objetivos propostos. É importante destacar que, apesar de possuir uma divisão das fases da análise de conteúdo, estas acontecem de forma simultânea.

A coleta de dados respeitou todos os preceitos éticos recomendados para a pesquisa com seres humanos e foi realizada após autorização dos órgãos responsáveis pelas Unidades de Saúde estudadas e pelo Comitê de Ética, sob parecer número 1.7858, além de Certificado de Apresentação para Apreciação Ética número 60309416.2.0000.0119.

A livre participação e o anonimato dos participantes foram garantidos por meio de um código alfanumérico composto pelas letras $\mathrm{P}$ e $\mathrm{M}$, que tipificam o participante e o município de Meleiro, respectivamente, e um número que atribuía à sequência do entrevistado(a), por exemplo, PM1, e assim sucessivamente.

\section{RESULTADOS E DISCUSSÃO}

Os resultados foram estruturados a partir de duas macrocategorias (satisfação e insatisfação dos profissionais da Estratégia Saúde da Família), compostas por seis subcategorias, as quais agregaram 102 trechos de falas, provenientes de um total de 17 códigos. Com vistas a não perder a totalidade do estudo e atender aos limites estruturais deste periódico, serão contemplados trechos de falas que têm relação a mais de um código, porém vinculado à mesma subcategoria.

\section{SATISFAÇÃO DOS PROFISSIONAIS DA ESTRATÉGIA SAÚDE DA FAMÍLIA}

A macrocategoria satisfação dos profissionais agregou um total 50 trechos de falas dos participantes vinculadas a oito códigos, conforme a Tabela 1.

Os sete códigos descritos foram agrupados em três subcategorias, a saber: o reconhecimento do trabalho na Estratégia Saúde da Família como satisfação; o processo de trabalho na Estratégia Saúde da Família como satisfação; os aspectos institucionais que colaboram para a satisfação. A Figura 1 ilustra a relação da macrocategoria, das subcategorias e dos códigos.

\section{O processo de trabalho na Estratégia Saúde da Família como satisfação}

Os participantes alegaram elementos vinculados ao processo de trabalho e à sua identificação com o modelo proposto pela ESF, como aspectos significativos para a satisfação dos

Tabela 1. Descrição dos códigos e número de trechos de falas relacionadas à satisfação dos profissionais de saúde do município de Meleiro/SC

\begin{tabular}{ccc} 
& \multicolumn{2}{c}{ Trechos de falas } \\
\cline { 2 - 3 } & $\mathbf{n}$ & $\%$ \\
Equipe e profissão & 14 & $28 \%$ \\
Organização do trabalho & 11 & $22 \%$ \\
Identificação com o trabalho & 10 & $20 \%$ \\
Estabilidade no emprego & 9 & $18 \%$ \\
Jornada de trabalho & 2 & $4 \%$ \\
Reconhecimento do trabalho & 2 & $4 \%$ \\
Satisfação do usuário & 2 & $4 \%$ \\
Total & 50 & $100 \%$ \\
\hline
\end{tabular}

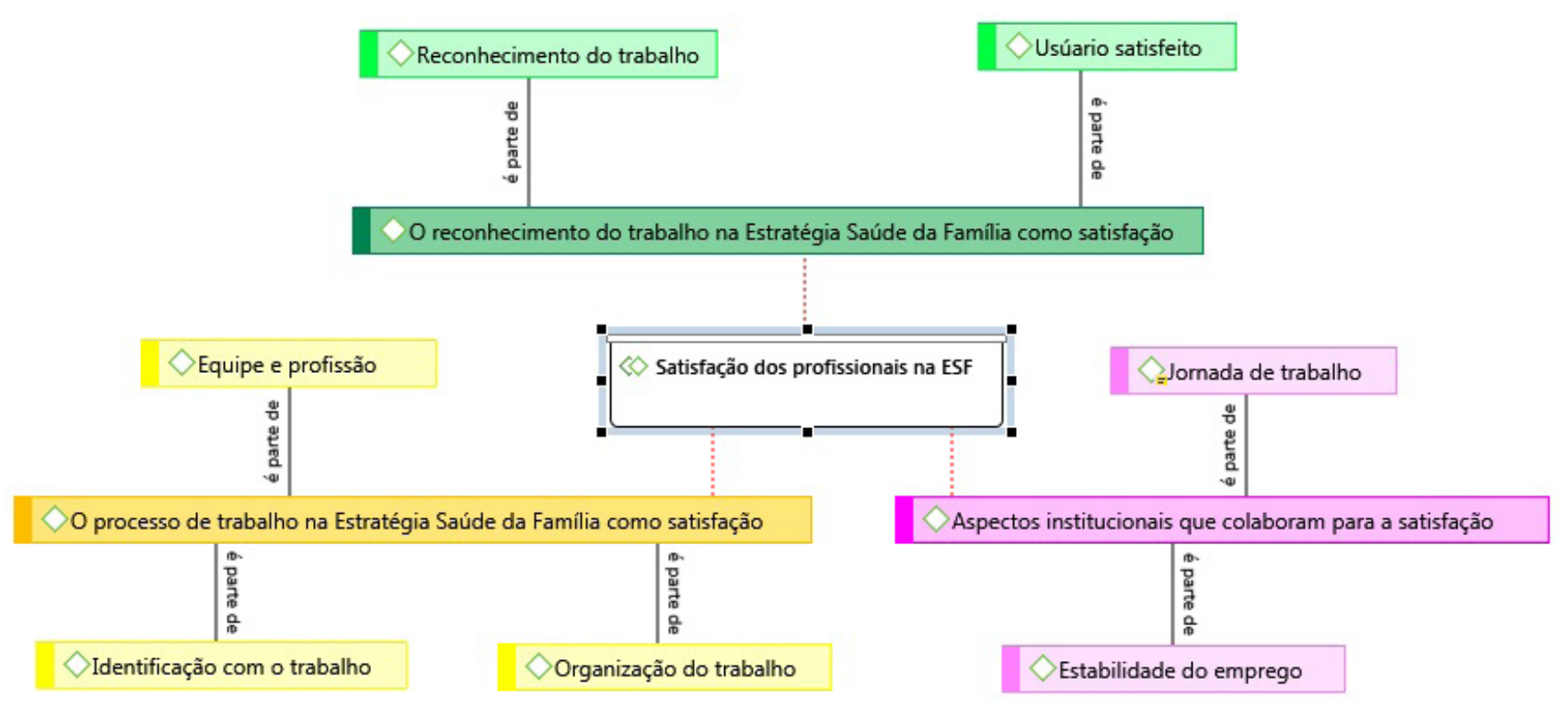

Figura 1. Relação entre a macrocategoria e os códigos vinculados à satisfação dos profissionais da Estratégia Saúde da Família do município de Meleiro/SC

Fonte: Dados da pesquisa, com auxílio do software Atlas.ti (2018) 
profissionais de saúde, conforme as falas a seguir: "A equipe toda trabalha unida, [...] é uma equipe bem entrosada, e é bem difícil tu trabalhar por aí e achar uma equipe como essa, eu vejo a transparência, isso me satisfaz" (PM2).

$\mathrm{O}$ trabalho em equipe pode ser considerado ferramenta para o exercício de uma das dimensões da integralidade ${ }^{6}$ e é uma possibilidade para ele ser construído de forma significante, trazendo benefícios ao paciente, oportunizando saberes e potencializando autonomia ao exercer sua profissão. A união entre os membros da equipe reflete no cuidado prestado aos usuários e corrobora a satisfação do profissional no desempenho de seu trabalho.

As redes de apoio que se estabelecem entre os profissionais devem ser valorizadas e fortalecidas para promoção da satisfação no lócus de atuação. Apoiar o profissional que integra a equipe nos mais diversos momentos em que se encontra deve ser uma prática cotidiana da equipe que integra a ESF. A fala a seguir reforça essa sustentação:

[...] o relacionamento com os colegas é bem tranquilo, cada um tem seus defeitos e suas qualidades, a gente tem que respeitar, não é todos os dias que estamos de bem com a vida, que você está com um sorriso no rosto, muitas vezes tu vens trabalhar com dor [...] tem que ser respeitado também o dia que aquele funcionário não está bem. Esse respeito é algo que me satisfaz (PM3).

A necessidade de respeito entre a equipe e de compreensão dos momentos pelos quais cada um passa no decorrer do exercício do trabalho deve ser algo contemplado nas práticas profissionais. É importante compreender que as relações que se estabelecem na equipe podem e devem ter suas diferenças, mas o respeito entre as posições diferenciadas precisa ser um compromisso ético do profissional.

Ao desenvolver o trabalho, o profissional de saúde procura aqueles com quem possa compartilhar os seus valores e as suas escolhas, alguém de confiança que contribua para atender a certas necessidades de saúde, buscando a eficiência das atribuições da $\mathrm{ESF}^{11}$. A cooperação no ambiente coletivo da ESF oferta elementos para construção da identidade singular do profissional e colabora para satisfação.

A identificação com o modo de produzir saúde oportunizado pela ESF é algo que contribui para satisfação. "Sinto-me realizada [...] porque você vai dentro da casa do paciente, você acaba criando um vínculo, que às vezes ficando só aqui dentro [ESF], ou num hospital, a gente não tem esse vínculo" (PM13).

A possibilidade de realizar ações diferentes de uma lógica institucional mais fechada, que direciona o profissional somente para a realização da assistência em saúde e que impede o estabelecimento de relações congruentes entre profissionais e usuários, é algo que corrobora a satisfação.

O trabalhar na ESF é vivenciar o território, senti-lo e acompanhar as pessoas que o habitam, e isso vai ao encontro de um dos atributos da APS, que é a longitudinalidade, caracterizada pela prestação do atendimento contínuo nas mais diversas fases da vida ${ }^{12}$.
O fato de gostar daquilo que você faz torna-se relevante, uma vez que abre possibilidade para construção de caminhos e para realizações na vida das pessoas que estão à sua volta e, com certeza, enriquece o ambiente de trabalho, proporcionando satisfação ao profissional.

\section{Aspectos institucionais que colaboram para a satisfação}

Os aspectos institucionais que proporcionam satisfação estão vinculados a ações que perpassam o campo da gestão em saúde, que se materializam em políticas de valorização e em garantia de vínculos de trabalho protegidos e de materiais e insumos para concretização da assistência.

As falas a seguir definem essa subcategoria: "[...] o regime de trabalho eu acho excelente a jornada de trabalho, eu acho que tem que ser assim mesmo, o povo precisa do profissional e ele tem que estar aqui" (PM2); "O ambiente do trabalho é bom para a gente porque todo material é novinho e dificilmente falta material" (PM6).

Para mim, estar concursada é a minha garantia de emprego, na verdade. Porque antes eu era contratada, e muda prefeito, muda um monte de coisa, e hoje em dia está bem difícil de conseguir emprego, então estar concursada é uma garantia, mas tu já ficas mais tranquila e satisfeita. Era o que eu queria (PM13).

A PNAB prevê uma jornada de 40 horas semanais para os profissionais, com exceção dos médicos ${ }^{2}$. O trabalho na ESF implica a dedicação de pelo menos um terço do tempo diário ao exercício profissional, sem contar o tempo de deslocamento até o local de trabalho.

Isso significa afirmar que os profissionais passam mais tempo trabalhando do que com suas famílias ou em atividades de lazer e descanso. Com esse tempo de dedicação ao trabalho, torna-se mais significativa a necessidade de estabelecer relações congruentes entre os membros da equipe e da equipe com seu objeto de trabalho (usuários).

O concurso foi outro aspecto ressaltado como promotor de satisfação. A estabilidade desse vínculo trabalhista permite que profissionais de saúde desenvolvam suas atividades de modo técnico com comprometimento ao usuário e sem interferência da gestão. Diante da atual conjuntura que o país se encontra, o simples fato de estar empregado para alguns já torna sua prática profissional mais satisfatória.

Apesar de os contratos por concurso público e de alguns com regime estatutário terem aumentado consideravelmente nos últimos anos, ainda existe um número significativo de profissionais que não é contratado pelas referidas regras ${ }^{13,14}$.

\section{O reconhecimento do trabalho na Estratégia Saúde da Família como satisfação}

A capacidade de ser reconhecido pela execução do seu trabalho nas práticas cotidianas da ESF e de conseguir 
visualizar a evolução clínica do paciente oportuniza satisfação, conforme as falas a seguir:

Ver o paciente sair contente pela forma que ele foi atendido pela gente, orientado. Muitas vezes eles só querem uma explicação, o que você puder ajudá-los já ficam satisfeito, isso me traz muita satisfação (PM8);

O sorriso do paciente quando está sendo curado. Isso não tem preço. É muito gratificante. Ir à casa do paciente e ver que teve uma boa resposta, que ele ficou feliz, que ele está contente (PM15).

O trabalho em saúde é composto por relações complexas que abrangem a necessidade de vínculo não só com o usuário, mas também com toda a sua família e com o ambiente no qual ele está inserido.

O reconhecimento por seu trabalho exige que o profissional identifique-se com os princípios do SUS e com os preceitos que regem a ESF. Os profissionais de saúde, ao realizarem o que gostam, não se sentem apenas executores de normas prescritas, mas atuam com possibilidade de exercer a criatividade, podendo reinventar-se constantemente no ato assistencial. Assim, o trabalho pode ser uma fonte de satisfação e de criação quando ele atende às necessidades, ou seja, transforma o objeto e o ser humano, e, dessa forma, o trabalhador se vê na obra que executa ${ }^{5}$.

\section{INSATISFAÇÃO DOS PROFISSIONAIS DA ESTRATÉGIA SAÚDE DA FAMÍLIA}

A macrocategoria insatisfação dos profissionais agregou um total 52 trechos de falas dos participantes vinculadas a códigos, conforme a Tabela 2.

Os dez códigos descritos foram agrupados em duas subcategorias, a saber: aspectos relacionados à gestão do trabalho em saúde como produtor de insatisfação; dificuldade de relacionamento e os desafios do trabalho na Estratégia Saúde da Família. A Figura 2 ilustra a relação da macrocategoria, das subcategorias e dos códigos

Tabela 2. Descrição dos códigos e número de trechos de falas relacionadas à insatisfação dos profissionais de saúde do município de Meleiro/SC

\begin{tabular}{ccc} 
Códigos & \multicolumn{2}{c}{ Trechos de falas } \\
\cline { 2 - 3 } & $\mathbf{n}$ & $\%$ \\
Relações com a equipe & 9 & $17 \%$ \\
Salário & 9 & $17 \%$ \\
Relações com o usuário & 9 & $17 \%$ \\
Possibilidade de adoecimento & 6 & $12 \%$ \\
Carência de profissionais & 6 & $12 \%$ \\
Sobrecarga de trabalho & 6 & $12 \%$ \\
Falta de comunicação & 2 & $4 \%$ \\
Estrutura física & 2 & $4 \%$ \\
Sistema de informatização & 2 & $4 \%$ \\
Condições de trabalho & 1 & $2 \%$ \\
Total & 52 & $100 \%$ \\
\hline
\end{tabular}

Aspectos relacionados à gestão do trabalho em saúde como produtor de insatisfação

As críticas à gestão em saúde no Brasil são diversas, amplas e mostram a dimensão dos problemas a serem enfrentados. Nos microespaços de saúde, as fragilidades da gestão se tonam ainda mais nítidas com consequências substanciais na insatisfação dos profissionais da Estratégia Saúde da Família. As falas a seguir ilustram alguns aspectos que foram agregados a essa categoria:

O salário deveria ser um pouco melhor pela carga horária. A gente vai se queixar, eles dizem: '[...] não está contente, tem outros que querem estar no seu lugar!' Tipo, um serviço tem que ter dois profissionais e se você dá conta, para que outro? Se vira eles dizem (PM7).

Falta de funcionário para dividir tarefas, funções, para sobrecarregar menos. A gente percebe que aqui no município foi criando programas e acumulando essa função para os profissionais, ao invés de contratarem mais gente para responderem (PM3).

[...] falta medicações, injetáveis, que a gente não faz aqui, porque o que me passaram é a falta de local para deixar em observação os pacientes. É mais isso, medicação injetável, um soro fisiológico, porque às vezes é bom, né (PM16).

[...] poderia estar me dedicando a estudar para um concurso, daí eu estou lá preparando palestra, as vezes tem que levar trabalho embora para colocar os nomes certos, empacota ou fazer algum estudo de caso, você fica sempre pensando no seu trabalho não tem lazer (PM2).

A insatisfação dos profissionais que atuam na ESF é influenciada pelas condições do trabalho, pela fragilidade na gestão e por problemas nas relações que permeiam o processo de trabalho em saúde

O salário, que não corresponde ao nível de exigência e de complexidade das profissões, é um dos principais motivos de insatisfação. Uma das alternativas para reversão dessa situação seria a implantação de um plano de cargos e salários, como um aspecto importante a ser considerado para a satisfação profissional. A ausência de planos de carreira é um dos fatores que levam à desmotivação e à rotatividade dos profissionais atuantes na ESF.

O excesso de trabalho como insatisfação é fortalecido pela quantidade significativa de programas e de ações que são de responsabilidade dos profissionais da ESF. Essas exigências prescritivas colaboram para que a assistência em saúde, em muitos momentos, não seja contemplada com qualidade.

A quantidade excessiva de trabalho é materializada por meio do processo burocrático que impera no cotidiano da ESF. A burocracia consiste necessariamente na priorização das normas e regras, de modo que, ao levar em conta os interesses da organização, desconsideram-se o profissional e a assistência por ele concebida, impedindo uma prática assistencial mais flexível do trabalho e, consequentemente, satisfatória ${ }^{6}$. 


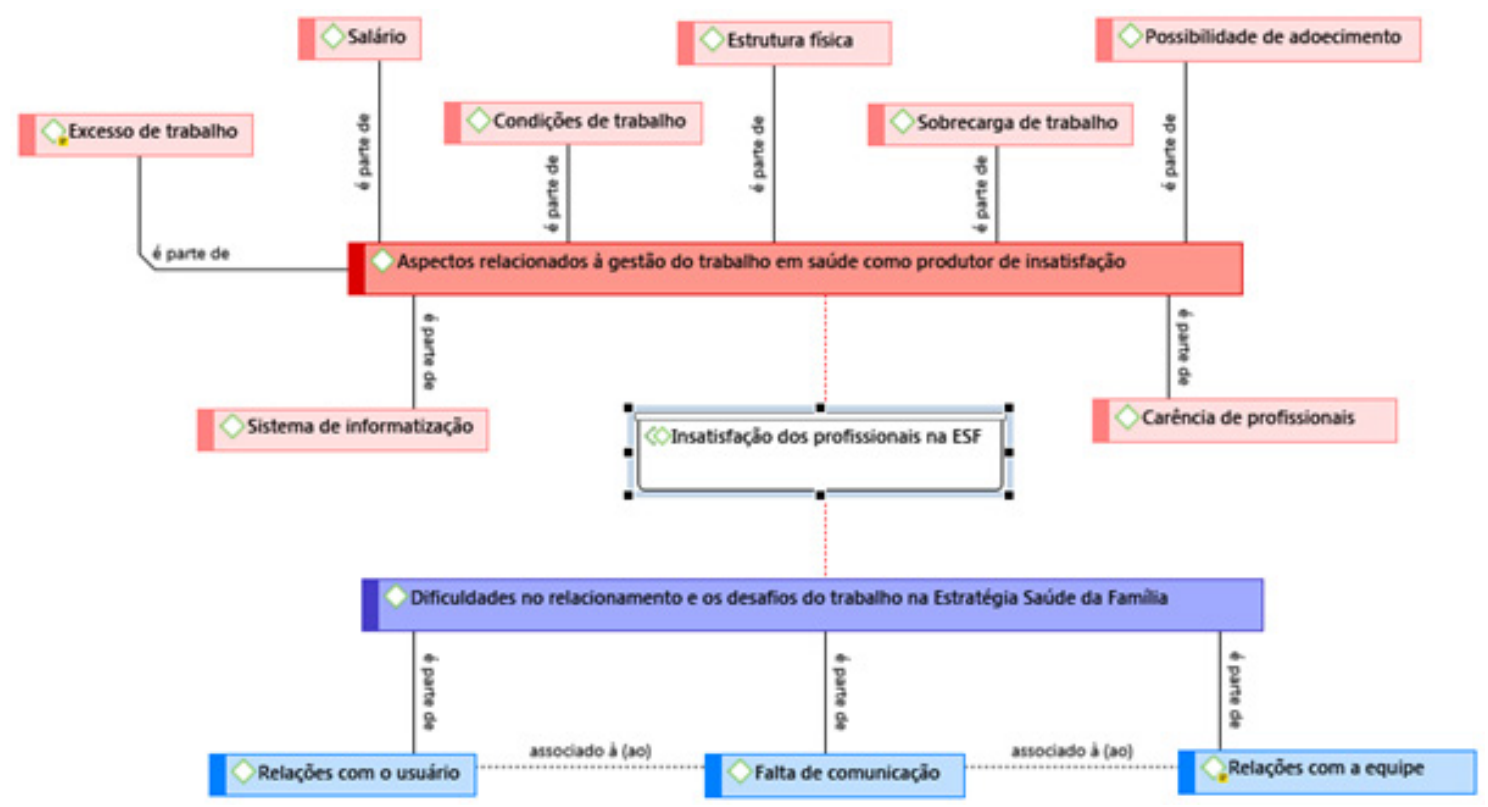

Figura 2. Relação entre a macrocategoria e os códigos vinculados à insatisfação dos profissionais da Estratégia Saúde da Família do município de Meleiro/SC

Fonte: Dados da pesquisa, com auxílio do software Atlas.ti (2018)

Os participantes relatam que o trabalho, muitas vezes, excede o expediente de exercício profissional na ESF, fazendo com que as muitas tarefas sejam levadas para o término no ambiente domiciliar. É necessário saber conciliar o trabalho com a vida pessoal, com vistas a manter um equilíbrio emocional para não adquirir complicações à sua saúde. A associação do trabalho com o ambiente externo fortalece que, no plano psicológico, não há divisão entre trabalho e fora dele ${ }^{15}$.

As dificuldades estruturais também foram reforçadas pelos participantes, as quais colaboram para o improviso de ações e sinalizam práticas de saúde no campo da gestão sem planejamento prévio. A oferta de uma estrutura física de qualidade é condição básica para o exercício do trabalho na ESF. Negligenciar esse aspecto é cooperar para a insatisfação dos profissionais de saúde e desconsiderar a importância do seu trabalho.

Não ofertar uma estrutura de trabalho adequada vai de encontro ao preconizado pela Política Nacional de Atenção Básica no que se refere à ambiência dos serviços²

\section{Dificuldades no relacionamento e os desafios do trabalho na Estratégia Saúde da Família}

As dificuldades impostas ao trabalho na ESF são diversas. O relacionamento entre a equipe, a gestão e os usuários, aliado à fragilidade comunicacional e à ausência de reconhecimento, implica desafios para melhoria do processo de trabalho. As falas a seguir sintetizam os resultados dessa subcategoria:

Falta de comunicação, quando eu e outra trabalhava a gente nunca sabia de nada, os recados que viam de fora, era só passado para as quatro, quando nós ficávamos sabendo era por boca de uma faxineira, elas não nos comunicavam e ainda não tem comunicação aqui dentro (PM1).

[...] o não reconhecimento pela população, às vezes tu agrada e parece que não serve mais para nada, as pessoas não reconhecem que não depende só de você. Tem coisa que não depende da gente, às vezes não tem um remédio, o exame vai demorar, não depende da gente, depende do fluxo. Um dos motivos que às vezes insatisfaz é esse (PM12).

No convívio entre a equipe de trabalho, principalmente no setor da saúde, são imprescindíveis a união e a efetivação do processo comunicacional, com vistas a exercer o trabalho de forma a não contribuir para problemas no relacionamento e, consequentemente, até possível adoecimento.

A relação entre os colegas de trabalho tem momentos que geram insatisfação, em razão do desconhecimento dos preceitos preconizados pela ESF, da postura do usuário na ânsia por uma assistência em saúde rápida e curativa e também da falta de comunicação e de organização dentro do âmbito de trabalho. O trabalho na ESF exige o estabelecimento de relações congruentes para que a assistência em saúde consiga ser mais resolutiva e supere processos insatisfatórios ${ }^{4}$.

As pessoas no local de trabalho necessitam aprender a interagir com o próximo, e o trabalho desenvolvido em equipe não se estabelece de modo automático, sendo necessário um processo de desenvolvimento de habilidades e capacidades, que vão desde a inteligência emocional até a vivência da dinâmica interpessoal e intergrupal.

A ESF é uma possibilidade inovadora para reordenar o modo de produzir saúde, mas possui inúmeras dificuldades 
que vêm emergindo ao longo de seu processo de implantação e desenvolvimento. Uma dessas dificuldades é a capacidade de manejo e de gerenciamento dos próprios profissionais que nelas estão inseridos ${ }^{16}$.

O profissional de saúde, quando não é reconhecido pelo seu trabalho, seja pela instituição, seja pela equipe ou pelos usuários, tem como resultado a insatisfação, e isso pode repercutir até mesmo na qualidade das atividades laborais. A ausência de atitudes de gratidão pelo serviço que o profissional exerce é um dos principais fatos que geram insatisfação para os profissionais da Estratégia Saúde da Família.

\section{CONSIDERAÇÕES FINAIS}

Os resultados permitiram identificar que a satisfação e a insatisfação dos profissionais da saúde que atuam na ESF de um município de pequeno porte são diferentes e se manifestam com diferentes níveis de intensidade no âmbito do trabalho.

Há necessidade de melhorias nas relações entre os atores envolvidos no exercício do trabalho institucionalizado na ESF, bem como na capacidade de entender a complexidade do jogo político que delimita o cenário das situações do trabalho em saúde. A forma como se estabelece esse processo refletirá para que o cotidiano da assistência na ESF seja um ambiente que promova satisfação.

Percebe-se também que há aspectos causadores de insatisfação profissional que transcendem a governabilidade dos profissionais, abarcando questões estruturais do sistema de saúde, como a carência de profissionais, a estrutura física e o sistema de informatização, e que acabam ocasionando sobrecarga de trabalho. Essas dificuldades podem ser dirimidas a partir da iniciativa e do comprometimento da gestão.

É preciso o reconhecimento de que há aspectos que dependem dos profissionais, como a necessidade de fortalecimento dos laços vinculares entre os diversos atores que atuam na ESF.

Por fim, a satisfação e a insatisfação exigem comprometimento da gestão em saúde e atuações diferenciadas dos profissionais para que seja possível explorar potencialidades e dirimir fragilidades existentes no âmbito da ESF.

\section{REFERÊNCIAS}

1. Brasil. Ministério da Saúde. Secretaria de Atenção à Saúde. Departamento da Atenção Básica. Histórico de Cobertura da Atenção Básica e Saúde da Família [Internet]. 2017. [acesso em: 2017 jul. 20]. Disponível em: http:// dab.saude.gov.br/portaldab/historicocoberturasf.php.

2. Brasil. Ministério da Saúde. Secretaria de Atenção à Saúde. Departamento de Atenção Básica. PNAB: Política Nacional de Atenção Básica. Brasília: Ministério da Saúde; 2012. (Série E. Legislação em Saúde; 1. ed)

3. Lima L, Pires DEP, Forte ECN, Medeiros F. Job satisfaction and dissatisfaction of primary health care professionals. Esc Anna Nery. 2014;18(1):17-24. http://dx.doi.org/10.5935/1414-8145.20140003.

4. Soratto J. Satisfação e insatisfação no trabalho de profissionais da Estratégia Saúde da Família [tese]. Florianópolis: Universidade Federal de Santa Catarina; 2016.

5. Marx K. O capital: crítica da economia política. 30. ed. Rio de Janeiro: Civilização Brasileira; 2012.

6. Dejours C. Psicodinâmica do trabalho e teoria da sedução Mello Neto GAR, tradutor. [Internet]. Psicol Estud. 2012; 17(3):363-371. [citado em 2017 mai. 27]. Disponível em: http://dx.doi.org/10.1590/S1413-73722012000300002.

7. Morse JM. Critical analysis of strategies for determining rigor in qualitative inquiry. Qual Health Res. 2015;25(9):1212-22. http://dx.doi. org/10.1177/1049732315588501. PMid:26184336.

8. Minayo MCS. Amostragem e saturação em pesquisa qualitativa: consensos e controvérsias [Internet]. Rev Pesquisa Qualit. 2017;5(7):01-12 [citado em 2017 jul. 1]. Disponível em: http://rpq.revista.sepq.org.br/index.php/rpq/ article/view/82.
9. Bardin L. Análise de conteúdo. São Paulo: Edições 70; 2011.

10. Friese S. Qualitative data analyis with ATLAS.ti. 2. ed. London: Sage; 2014.

11. Scherer MDA, Pires DEP, Jean R. A construção da interdisciplinaridade no trabalho da equipe de saúde da família [Internet]. Ciênc. saúde coletiva. 2012;18(11):3203-12 [acesso em 2017 abr 17]. Disponível em: http://dx.doi. org/10.1590/S1413-81232013001100011.

12. Oliveira MAC, Pereira IC. Atributos essenciais da Atenção Primária e a Estratégia Saúde da Família. Rev Bras Enferm. 2013;66(spe):158-64. http:// dx.doi.org/10.1590/S0034-71672013000700020.

13. Girardi S, Carvalho CL, Maas LWD, Farah J, Freire JA. O Trabalho precário em saúde: tendências e perspectivas na estratégia da saúde da família. Divulgação em Saúde para Debate. 2010;45:11-23 .

14. Garcia ACP. et al. Análise da organização da Atenção Básica no Espírito Santo: (des)velando cenários. Saúde Debate. 2014;38(N. esp.):221-236.

15. Dejours C, Cardoso MR. Entrevista Chrstophe Dejours [Internet] Ágora. 2001;4(2);89-94. [acesso em 2017 fev. 15]. Disponível em: http://www. scielo.br/pdf/agora/v4n2/v4n2a07.pdf.

16. Trindade LL, Pires DEP, Amestoy SC, Forte ECN, Machado FL, Bordignon M. Trabalho na Estratégia Saúde da Família: implicações nas cargas de trabalho de seus profissionais. Cogitare Enferm 2014;19(3):528-35.

Recebido em: Jul. 17, 2017 Aprovado em: Mai. 27, 2018 